\title{
Высокочастотный 8-разрядный БиКМОП АЦП
}

\author{
Г. Алексеев ${ }^{1}$, В.Репин, к. т.н. ${ }^{1}$, И. Мухин, к. т. н. ${ }^{1}$, М. Дроздецкий ${ }^{1}$
}

УДК 621.38 | ВАК 05.27 .01

\begin{abstract}
В НИимА «Прогресс» разработан двухкаскадный конвейерный 8-разрядный аналого-цифровой преобразователь (АЦП). Предложенные архитектурные решения позволяют обеспечить высокую точность преобразования при сравнительно низком энергопотреблении, что подтверждается экспериментальными исследованиями на частотах до 1 ГГц. Динамические параметры АЦП: соотношение сигнал / шум (SNR) - 47 дБ, эффективное число разрядов (ENOB) - 7,3, коэффициент искажения динамического диапазона (SFDR) - 42 дБ. Статические параметры АЦП: дифференциальная (DNL) и интегральная (INL) нелинейности - менее 0,5 М3P.
\end{abstract}

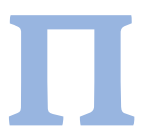

о мере увеличения скорости обработки цифровой информации повышаются требования кбыстродействию АЦП. Наиболее распространенный метод построения СВЧ АЦП-использование параллельной архитектуры. Несмотря на преимущества в быстродействии и простоте реализации, для этой структуры характерны ограничения в разрядности АЦП (не более десяти), так как с добавлением разряда количество элементарных ячеек преобразования удваивается. Таким образом, растущее энергопотребление может быть критичным в портативных устройствах [1].

Улучшенной версией параллельного АЦП является АЦП с предварительной аналоговой сверткой. Основная идея данной архитектуры - отдельное преобразование старших и младших разрядов, то есть двумя отдельными АЦП. На вход первого АЦП поступает исходный сигнал для преобразования старших разрядов. На второй АЦП сигнал приходит послеаналоговой свертки, производимой каскадами усилителей. Такая архитектура позволяет спроектировать АЦП средней разрядности (10-14 разрядов) с высокой скоростью преобразования, однако при этом повышаются требования к точности аналоговой свертки и увеличивается потребляемая мощность.

Наряду с этими двумя типами архитектур распространены конвейерные АЦП, выходные коды в которыхпреобразуются поочередно в каскадах преобразования. Между каскадами аналоговый сигнал передается при помощи цифро-аналоговых преобразователей (ЦАП) и аналоговых сумматоров. По конвейерной архитектуре возможно получить АЦП высокой разрядности (14-16 разрядов), со средним быстродействием и с низкой потребляемой мощностью. Сложность реализации такого АЦП заключается в обеспечении точности передачи аналогового сигнала между каскадами. Ключевой особенностью конвейерныхАЦП является уникальная и сложная схема корректировки неизбежных ошибок в преобразовании.
Рассмотрим 8-разрядный АЦП, спроектированный на основе SiGe БиКМОП-технологии по проектным нормам 250 нм. Основное преимущество данного изделия-возможность получения высокой точности преобразования сиспользованием общеизвестных схемотехнических решений.

\section{ОБЗОР АРХИТЕКТУРЫ}

Общая структура предложенной архитектуры АЦП представлена на рис. 1. В структурной схеме АЦП расположены два симметричных канала, тактовые сигналы которых сдвинуты по фазе на 180. Каждый канал состоит из устройства выборки и хранения (УВХ) и двух каскадов преобразования. Входной сигнал сохраняется на выходах УВХ и параллельно

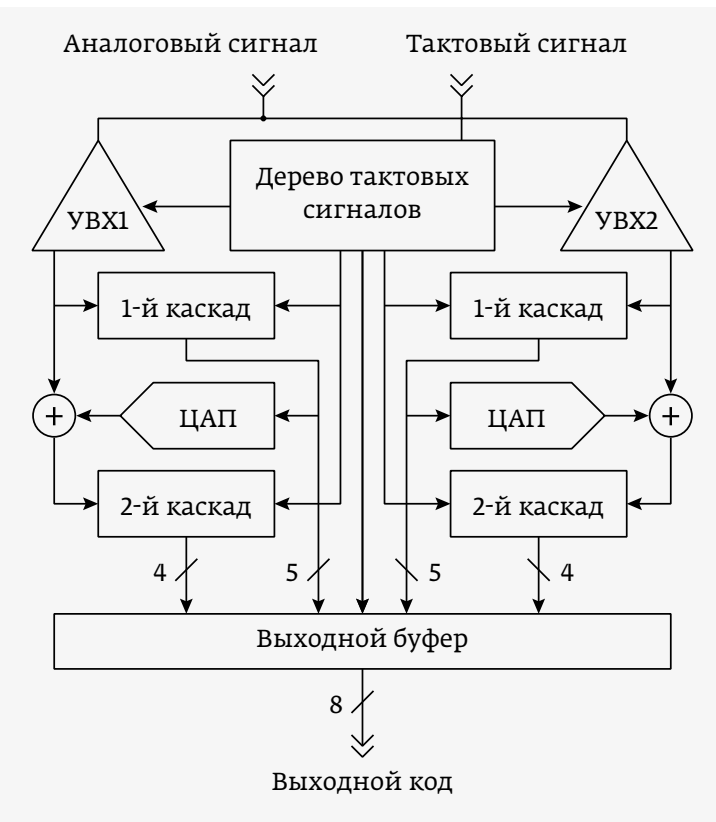

Рис. 1. Структурная схема АЦП 


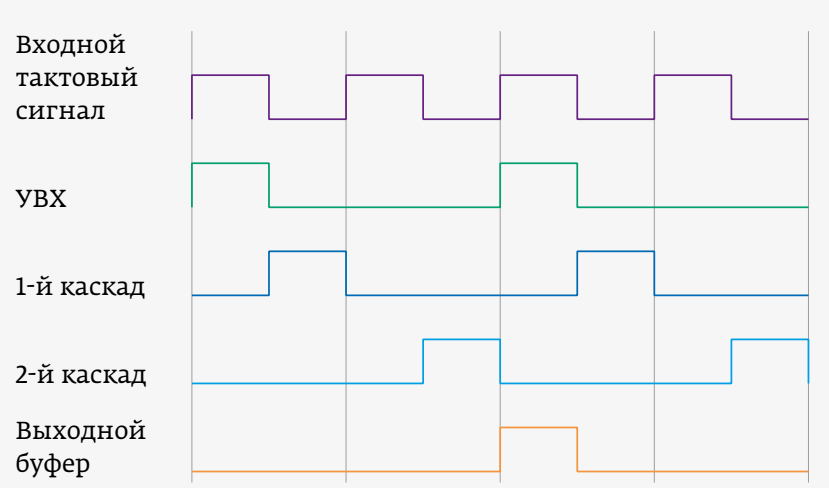

Рис. 2. Диаграмма тактовых сигналов для одного канала

передается к каскадам преобразования: к первому каскаду напрямую, ко второму - после вычитания из него результатов преобразования первого каскада. Вычитание производится при помощи ЦАП и аналогового сумматора. Для повышения точности преобразования используется избыточная разрядность. Таким образом, первый каскад выполняет преобразование четырех разрядов, второй-пяти. Выходной буфер, в свою очередь, производит сложение с поразрядным перекрытием и выводит итоговый результат в формате LVDS.

Диаграмма тактовых сигналов одного из каналов представлена на рис. 2. Разница во времени между каналами составляет один такт входного тактового сигнала. В режиме хранения (РХ) сигнал с выходов УВХ доставляется к каскадам преобразования. Выходной буфер выдает итоговый результат после того, как оба каскада произведут преобразование.

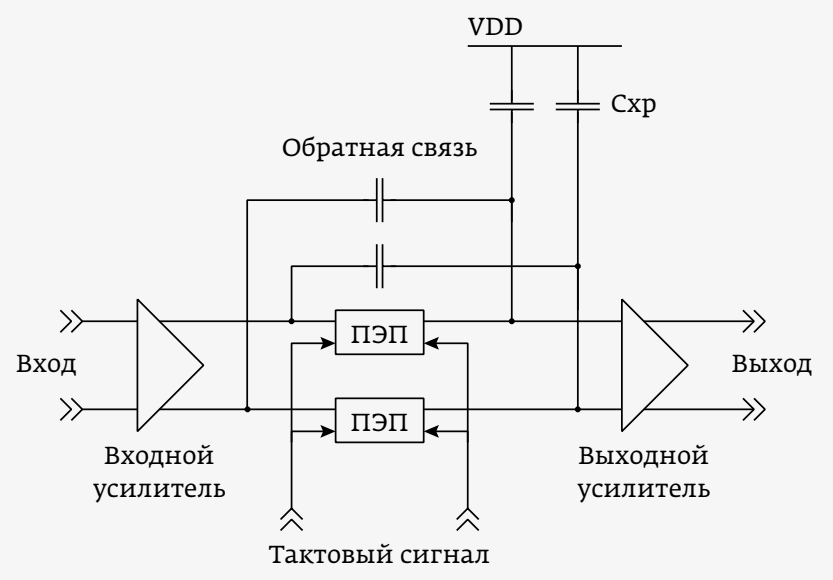

Рис. 3. Структурная схема УВХ

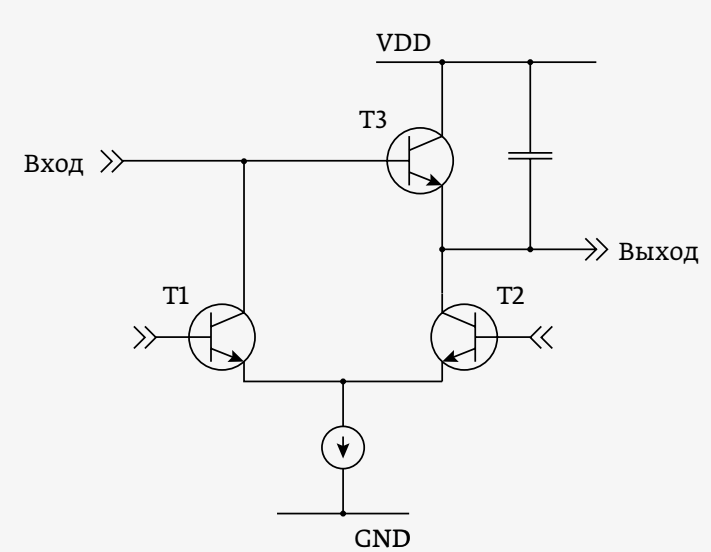

Рис. 4. Переключаемый эмиттерный повторитель

\section{РЕАЛИЗАЦИЯ ОСНОВНЫХ БЛОКОВ}

УВХ квантует и дискретизирует входной аналоговый сигнал, сохраняя его постоянным в режиме хранения. Будучи входным каскадом АЦП, УВХ - один из ключевых элементов, поскольку может оказывать влияние на точность преобразования из-за недостаточных динамического и частотного диапазонов. На рис. 3 представлена известная схема УВХ на биполярных транзисторах [2].

Дискретизация в схеме производится переключаемыми эмиттерными повторителями (ПЭП) (рис. 4). Упрощенная версия ПЭП состоит из дифференциальной пары транзисторов, нагруженной конденсатором хранения (Схр). В рамках

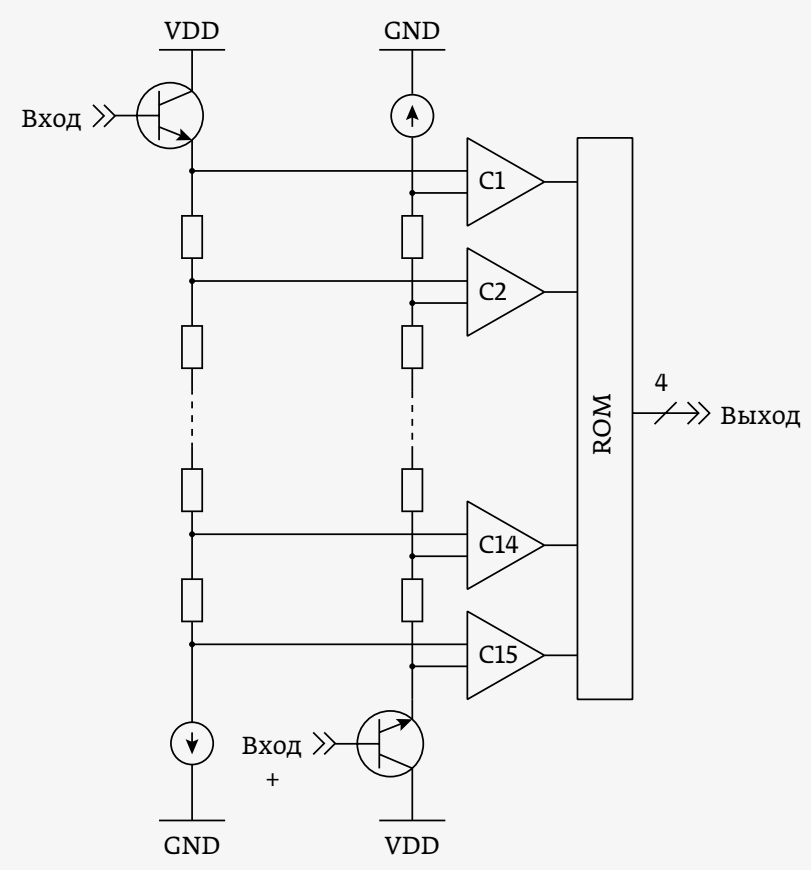

Рис. 5. Первый каскад преобразования 


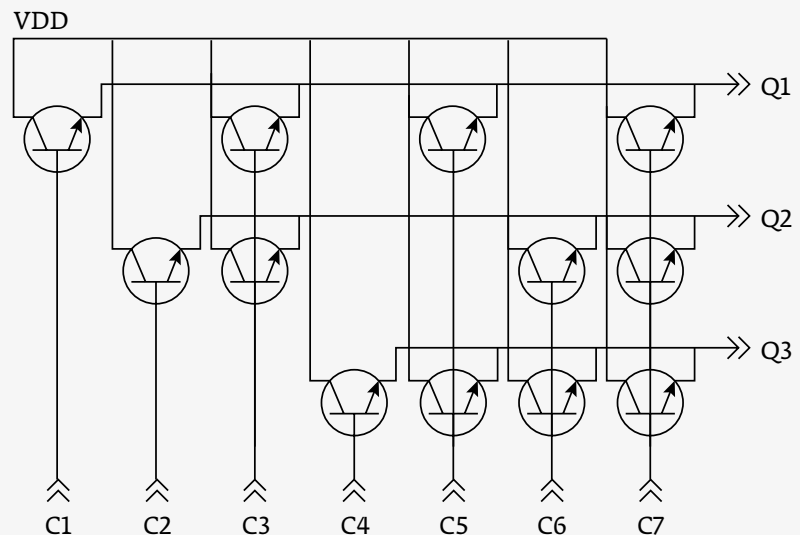

Рис. 6. ROM-матрица

режима слежения ток течет через правое плечо (T2, T3), заряжая конденсатор Схр. В режиме хранения ток переключается на транзистор П. В этот момент конденсатор отключается от входного сигнала и начинает раздавать сохраненное значение на каскады преобразования. Благодаря биполярным транзисторам частотный диапазон данного УВХ с запасом

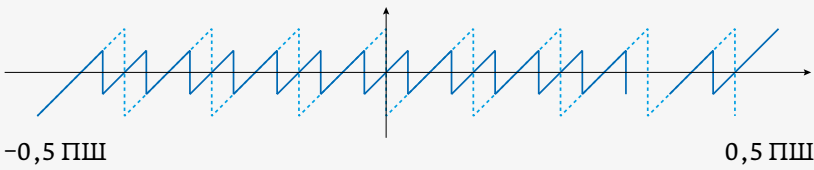

Рис. 7. Входной сигнал второго каскада

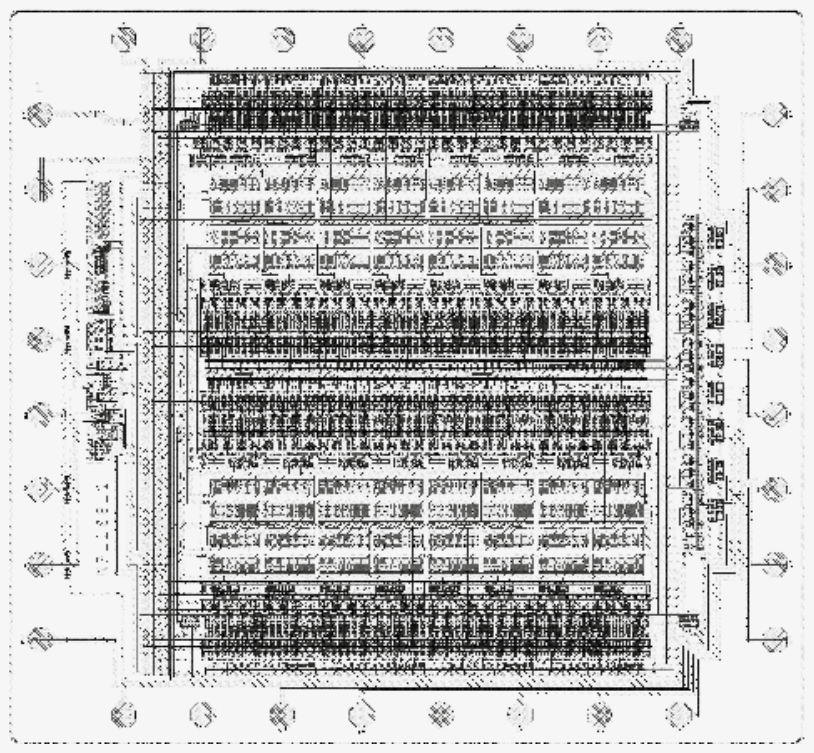

Рис. 8. Топология АЦП

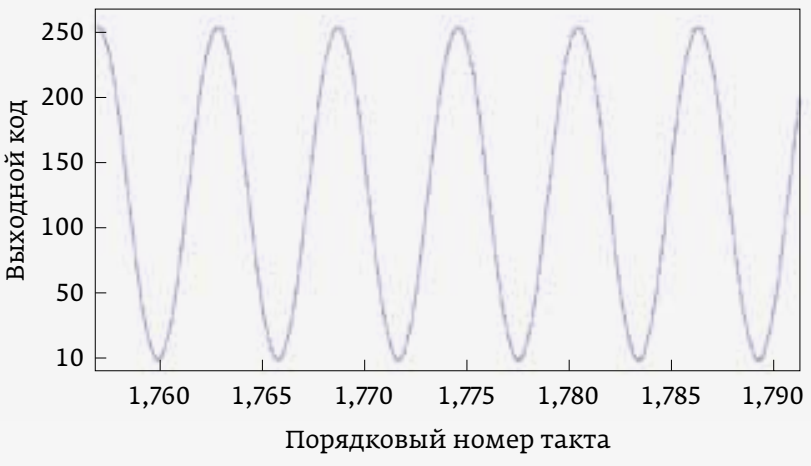

Рис. 9. Временная развертка выходного кода

охватывает входной аналоговый сигнал в первой зоне Найквиста. Однако для быстродействия дифференциальныхпар необходима достаточная величина тока. Кроме того, использование биполярных транзисторов приводит к токам утечки с конденсатора, тем самым сохраненный сигнал со временем изменяется. В целях компенсации потерь применяется емкостная отрицательная связь. Обратная связь особенно необходима при использовании УВХ совместно с несколькими каскадами преобразования.

Кроме ПЭП и обратных связей, УВХ включает в себя входной и выходной буферы с простыми дифференциальными усилителями.

Первый каскад преобразования представляет собой простой 4-разрядный параллельный АЦП (рис. 5), состоящий из резистивной цепи и 15 компараторов. Для реализации избыточной разрядности резистивная цепь сдвинута на 1/32 полной шкалы. Такой тип каскадов часто называют 3,5-разрядным.

У большей части БиКМОП-компараторов достаточные параметры для их применения в АЦП с частотой преобразования до1ГГц. В данной работе использован простейший стробируемый компаратор.

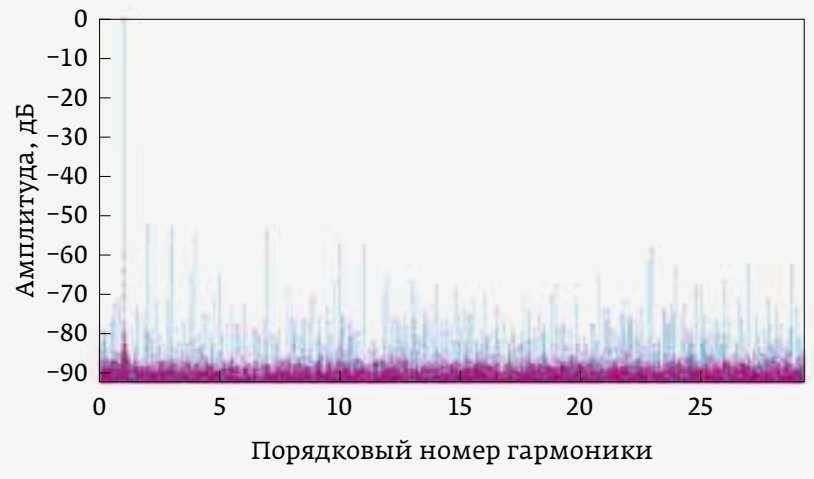

Рис. 10. Спектральная характеристика 
Термометрический код с выхода компараторов попадает на ROM-матрицу, которая преобразует его в прямой двоичный код. Для примера на pис. 6 представлен 3-разрядный ROM. Преимущества использования ROMматрицы в малой занимаемой площади и низкой задержке.

Стоит отметить, что несмотря на небольшую занимаемую площадь, ROMматрица отличается длинными выходными эмиттерными шинами. При построении топологии матрицы на кристалле это необходимо учитывать, чтобы по возможности уменьшить паразитные емкости.

Структура второго каскада преобразования аналогична структуре первого. Отличие заключается в разрядности, то есть в количестве компараторов (31 для 5-рязрядного каскада). Как уже говорилось, аналоговый сигнал на второй каскад приходит после вычитания из него результатов преобразования первого каскада. В итоге на второй каскад поступает сигнал, изображенный на рис. 7.

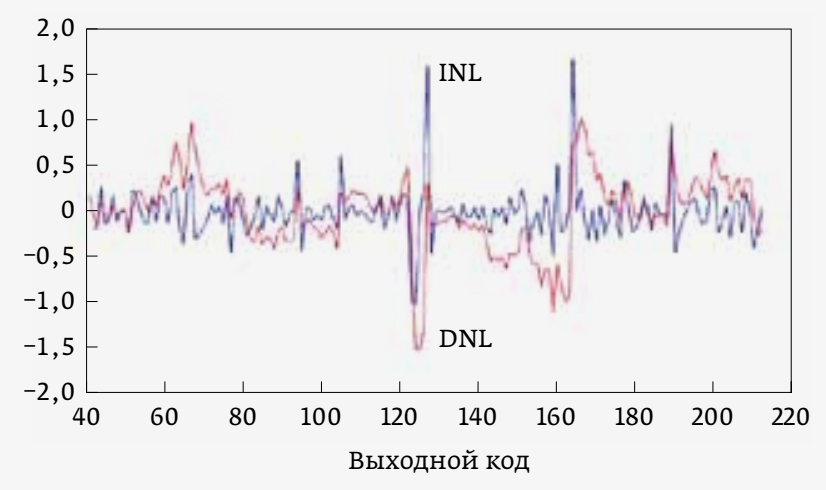

Рис. 11. Статические параметры

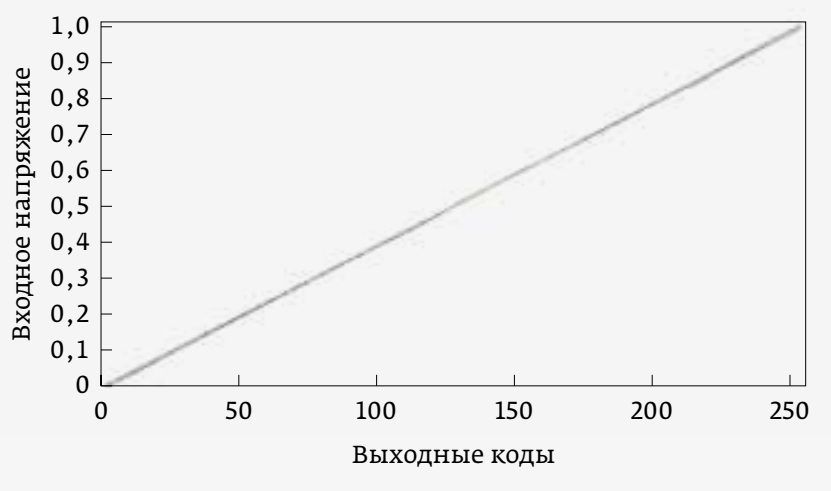

Рис. 12. Передаточная характеристика
Все полученные двоичные коды поступают на выходной буфер, вычисляющий поразрядную сумму. Итоговые результаты с каждого канала объединяются при помощи мультиплексора. Для сохранения быстродействия цифровые ячейки выполнены в ЭСЛ-логике.

Топология кристалла разработанного АЦП представлена на рис. 8.

\section{ЭКСПЕРИМЕНТАЛЬНЫЕ РЕЗУЛЬТАТЫ}

8-разрядный АЦП спроектирован с использованием SiGe БиКМОП технологии по проектным нормам 250 нм. На рис. 9 изображена временная развертка выходного десятичного кода для полной шкалы АЦП. Частота входного сигнала составляет 17 МГц, частота тактового -1ГГц. Динамические параметры вычислены по спектральной характеристике выходного кода (рис. 10). Зависимость статических параметров от амплитуды входного сигнала показана на рис. 11, соответствие выходного кода входному сигналу - на рис. 12.

В таблице приведены результаты сравнения зарубежных СВЧ АЦП с разработанной микросхемой 5408НВ015.

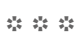

В статье представлен 8-разрядный СВЧ АЦП для работы в частотном диапазоне до 1 ГГц. Особенность предложенных схемотехнических решений - отсутствие трудоемких методов корректировок и подгонок параметров в процессе производства.

Как показали результаты измерения готовых микросхем, по своим характеристикам они соответствуют современным зарубежным аналогам при приемлемой себестоимости изделия.

\section{ЛИТЕРАТУРА}

1. Kester W. Analog-Digital Conversion // Analog Devices, Inc. Printed in the United States of America. ISBNO-916550-27-3. 2004. P. 120.

2. Vorenkamp P. and Verdaasdonk J.P.M. Fully bipolar, 120-Msample 10b Track-and-Hold Circuit, 1992. 